\title{
Increased prevalence of poor sulphoxidation in patients with rheumatoid arthritis: effect of changes in the acute phase response and second line drug treatment
}

\author{
Paul Emery, Helen Bradley, Andrew Gough, Val Arthur, Ronald Jubb, Rosemary Waring
}

\begin{abstract}
A minority of normal subjects have an impaired ability to oxidise sulphur, which is associated with an increased risk of side effects when they receive sulphur containing drugs. In 114 patients with rheumatoid arthritis a greatly increased prevalence of poor sulphoxidation was found in $82(72 \%)$ patients compared with $70 / 200(35 \%)$ healthy controls, 45/121 (37\%) controls matched for age, and 4/35 (11\%) of the normal aged general population. In a longitudinal study of 37 patients there was no significant alteration in sulphoxidation status after the introduction of a second line drug or with marked changes in the acute phase response. It seems, therefore, that the poor sulphoxidation status in patients with RA is not an epiphenomenon and may be an important factor in determining the clinical features of rheumatoid disease.
\end{abstract}

The ability to oxidise the sulphur compound $S$ carboxymethyl-L-cysteine seems to be largely genetically determined. ${ }^{1}$ In normal populations there is great individual variation, with a minority (about 35\%) having a reduced ability to carry out this reaction (poor sulphoxidisers). ${ }^{2}$ Such subjects have an increased prevalence of side effects to sulphur containing drugs; this has been shown, for example, in patients with rheumatoid arthritis (RA) treated with either Dpenicillamine $^{3}$ or with sodium aurothiomalate. ${ }^{4}$ The same studies suggested that poor sulphoxidation of $S$-carboxymethyl-L-cysteine was more common in patients with RA than in control groups; a finding that was difficult to interpret because of selection bias. Furthermore, in RA the assessment of patients is complicated by the abnormal acute phase response and by multiple drug treatment. Recently, the prevalence of poor sulphoxidation has been shown to be increased in other autoimmune disorders ${ }^{5} 6$ but not in patients with non-autoimmune inflammation or in elderly subjects. ${ }^{27}$ As these observations have implications for disease management and pathogenesis we undertook a more definitive study to establish the stability of sulphoxidation status in patients with RA taking account of these variables.

Therefore, this study investigated both cross sectionally and longitudinally the influence of major changes of the acute phase response and of the introduction of second line drugs on sulphoxidation status.

Patients and methods

PATIENTS

All patients fulfilled the American Rheumatism
Association 1987 criteria for RA. Ethical appraisal was obtained and all patients gave their informed written consent. On the day of testing a full examination was made, the joint score was obtained, and blood was taken for determination of rheumatoid factor and $\mathrm{C}$ reactive protein (CRP).

Two studies were carried out. The first was of 114 consecutive patients, both inpatients and outpatients, seen in clinical practice. Of the patients approached to undertake testing, only two patients refused. The second study examined prospectively sulphoxidation ability before and three months after the introduction of a 'second line/disease modifying' drug. There were three different control groups: (a) 121 hospital patients with no evidence of inflammatory disease; (b) 200 normal volunteers (studied in $1984)^{8}$; and (c) 35 normal elderly subjects with no clinical disease and receiving no drugs. Patients followed up longitudinally were subdivided according to their acute phase response: those in whom the CRP and erythrocyte sedimentation rate (ESR) had diminished by $50 \%$ by the time of retesting were labelled responders, whereas those in whom the CRP and ESR did not change by more than $10 \%$ were defined as non-responders.

\section{SULPHOXIDATION STATUS}

The sulphoxidation ability of each subject was determined as follows. After an overnight fast patients emptied their bladders and took a single $750 \mathrm{mg}$ oral dose of carbocisteine; a light breakfast was permitted one hour later and any regular drugs were delayed until three hours after the start of the test. Urine passed in the subsequent eight hours was collected, the volume recorded, and an aliquot stored at $-20^{\circ} \mathrm{C}$ until analysed by planimetric densitometry. ${ }^{8}$ The patients' sulphoxidation ability was expressed in the form of a ratio, with the percentage of administered dose excreted as sulphides divided by the percentage sulphoxide metabolite to give the sulphoxidation index (SI). For patients taking D-penicillamine, which interferes with this assay, the metabolites were separated by high performance liquid chromatography. A good sulphoxidiser was defined on the basis of previous data as having a ratio less than $\operatorname{six}(\mathrm{SI}<6 \cdot 0)$.

\section{Results}

CROSS SECTIONAL STUDY

Tables 1-3 give details of patients and controls. Both the median SI and the percentage of 
patients with SI $>6.0$ (poor sulphoxidation) were significantly greater $(p<0.001)$ in the patients with RA than in the control groups (table 1).

Table 2 shows the percentage of poor sulphoxidisers in patients taking different second line drugs. There were no significant differences between the SI values of the patients taking various drugs.

Table 3 compares various measures of disease

Table 1 Cross sectional study: comparison of the sulphoxidation index $(S I)$ in patients with rheumatoid arthritis $(R A)$ and in controls

\begin{tabular}{llll}
\hline Patient groups & $\begin{array}{l}\text { Mean (SD) } \\
\text { age } \\
\text { (years) }\end{array}$ & $\begin{array}{l}\text { SI } \\
\text { median }\end{array}$ & $\begin{array}{l}\text { No }(\%) \\
\text { with } \\
S I>6 \cdot 0\end{array}$ \\
\hline RA ( $\mathrm{n}=114)$ & $56(15)$ & 80 & $82(72)$ \\
Hospital controls $(\mathrm{n}=121)$ & $61(9)$ & $3 \cdot 4^{*}$ & $45(37)$ \\
Normal controls $(\mathrm{n}=200)$ & $34(12)$ & $2 \cdot 3^{*}$ & $70(35)$ \\
Aged controls $(\mathrm{n}=35)$ & $77(7)$ & $1 \cdot 8^{*}$ & $4(11)$ \\
\hline
\end{tabular}

${ }^{*} p<0.001$ compared with RA (Wilcoxon rank sum test).

Table 2 Cross sectional study: effect of second line drugs on sulphoxidation index (SI) in patients with rheumatoid arthritis

\begin{tabular}{lclc}
\hline Drug & $\begin{array}{l}\text { Number } \\
\text { of patients }\end{array}$ & $\begin{array}{l}\text { SI value } \\
\text { (mean }(S D))\end{array}$ & $\begin{array}{l}\text { No }(\%) \\
\text { with } S I>6\end{array}$ \\
\hline D-Penicillamine & 21 & $30(37)$ & $16(77)$ \\
Prednisolone & 16 & $42(39)$ & $10(63)$ \\
Sulphasalazine & 16 & $32(38)$ & $7(56)$ \\
Sodium aurothiomalate & 9 & $30(38)$ & $5(56)$ \\
Methotrexate & 6 & $41(43)$ & $5(84)$ \\
Other & 32 & $32(39)$ & $28(88)$ \\
All & 114 & $34(39)$ & $82(72)$ \\
\hline
\end{tabular}

No significant differences by Wilcoxon rank sum test.

Table 3 Cross sectional study: correlation between sulphoxidation index and disease parameters in 114 patients with rheumatoid arthritis

\begin{tabular}{lcl}
\hline Parameter & $r$ Value & $p$ Value \\
\hline C reactive protein & -0.146 & 0.31 \\
Erythrocyte sedimentation rate & 0.003 & 0.98 \\
Rheumatoid factor & 0.029 & 0.77 \\
Age & 0.01 & 0.89 \\
\hline
\end{tabular}

activity and the SI. It can be seen that there was no correlation between SI values and the parameters CRP, ESR, rheumatoid factor, or age.

\section{LONGITUDINAL STUDY}

Table 4 shows the SI values before and three months after the introduction of a disease modifying drug. Overall, there was no significant change in the mean SI after drug treatment. The changes in SI were small, and no pattern was discernible for individual drugs with the possible exception of patients receiving methotrexate, in whom the mean SI rose from 34 to 54, but was not significant. Most importantly, no patient had a change in sulphoxidation phenotype.

Reanalysis according to whether patients had had a significant suppression of the acute phase response again showed no significant differences (table 5).

\section{Discussion}

There is increasing interest in the associations between defective metabolic pathways and disease processes, both naturally occurring and iatrogenic. An increased prevalence of poor sulphoxidation (using $S$-carboxymethyl-Lcysteine as probe) in patients with RA has been previously suggested ${ }^{3}$ and has been confirmed in this study, where $82(72 \%)$ of the 114 patients with RA had SI values $>6.0$. This is in comparison with $70 / 200(35 \%)$ from control volunteer populations and 45/121 (37\%) in hospital patients matched for age. Interestingly, age itself seems to have no effect on SI values; in a small group of 12 healthy, aged volunteer controls the number of poor sulphoxidisers was actually reduced at $11 \%$. One possible explanation for this finding is that poor sulphoxidation is a bad prognostic factor perhaps because of its association with autoimmunity; hence its relative infrequency in the normal elderly population. All patients and controls were dosed with $S$ -

Table 4 Longitudinal study: effect of introduction of second line drugs on sulphoxidation index (SI)

\begin{tabular}{|c|c|c|c|c|}
\hline Drug & $\begin{array}{l}\text { Number } \\
\text { of patients }\end{array}$ & $\begin{array}{l}\text { Mean }(S D) \\
S I \text { at start, } \\
T_{0}\end{array}$ & $\begin{array}{l}\text { Mean }(S D) \\
\text { SI at } \\
3 \text { months, } T_{3}\end{array}$ & $\begin{array}{l}\text { No (\%) with } \\
\text { SI >6.0 } \\
\left(\text { at } T_{0} \text { and } T_{3}\right)\end{array}$ \\
\hline $\begin{array}{l}\text { D-Penicillamine } \\
\text { Prednisolone } \\
\text { Sulphasalazine } \\
\text { Sodium aurothiomalate } \\
\text { Methotrexate } \\
\text { Other } \\
\text { All }\end{array}$ & $\begin{array}{r}12 \\
4 \\
7 \\
4 \\
6 \\
4 \\
37\end{array}$ & $\begin{array}{l}38(34) \\
47(40) \\
40(38) \\
22(38) \\
34(38) \\
42(43) \\
37(37)\end{array}$ & $\begin{array}{l}49(38) \\
44(43) \\
44(39) \\
29(36) \\
54(39) \\
30(38) \\
44(39)\end{array}$ & $\begin{array}{r}10(83) \\
3(75) \\
6(86) \\
2(50) \\
4(67) \\
3(75) \\
28(76)\end{array}$ \\
\hline
\end{tabular}

Table 5 Longitudinal study: effect of acute phase response on sulphoxidation index $(S I)$ in responders* and non-responders*

\begin{tabular}{|c|c|c|c|c|c|c|c|c|}
\hline \multirow[t]{2}{*}{ Drug } & \multicolumn{4}{|c|}{ Responders } & \multicolumn{4}{|c|}{ Non-responders } \\
\hline & $\begin{array}{l}\text { No of } \\
\text { patients }\end{array}$ & $\begin{array}{l}\text { Mean }(S D) \\
\text { SI at } \\
\text { start, } T_{0}\end{array}$ & $\begin{array}{l}\text { Mean }(S D) \\
S I \text { at } \\
3 \text { months, } T_{3}\end{array}$ & $\begin{array}{l}\text { No }(\%) \text { with } \\
S I>6.0 \\
\left(\text { at } T_{0} \text { and } T_{3}\right)\end{array}$ & $\begin{array}{l}\text { No of } \\
\text { patients }\end{array}$ & $\begin{array}{l}\text { Mean }(S D) \\
\text { SI at } \\
\text { start, } T_{0}\end{array}$ & $\begin{array}{l}\text { Mean }(S D) \\
\text { SI at } \\
3 \text { months, } T_{3}\end{array}$ & $\begin{array}{l}\text { No (\%) with } \\
\text { SI >6.0 } \\
\left.\text { (at } T_{0} \text { and } T_{3}\right)\end{array}$ \\
\hline $\begin{array}{l}\text { D-Penicillamine } \\
\text { Prednisolone } \\
\text { Sulphasalazine } \\
\text { Sodium aurothiomalate } \\
\text { Methotrexate } \\
\text { All }\end{array}$ & $\begin{array}{r}7 \\
1 \\
6 \\
4 \\
6 \\
24\end{array}$ & $\begin{array}{l}50(38) \\
26 \\
50(40) \\
28(45) \\
34(38) \\
35(37)\end{array}$ & $\begin{array}{l}60(34) \\
60(39) \\
51(39) \\
29(36) \\
55(39) \\
47(37)\end{array}$ & $\begin{aligned} 6 & (86) \\
1 & (100) \\
5 & (83) \\
2 & (50) \\
4 & (67) \\
18 & (75)\end{aligned}$ & $\begin{array}{l}5 \\
3 \\
1 \\
0 \\
0 \\
9\end{array}$ & $\begin{array}{l}26(33) \\
57(46) \\
30 \\
41(34)\end{array}$ & $\begin{array}{l}35(41) \\
49(39) \\
80 \\
60(32)\end{array}$ & $\begin{array}{l}4(80) \\
2(67) \\
1(100) \\
7(88)\end{array}$ \\
\hline
\end{tabular}

${ }^{*}$ Responder=those in whom CRP and ESR had diminished by $50 \%$ by the time of retesting; non-responder=those in whom CRP and ESR did not change by more than $10 \%$. 
carboxymethyl-L-cysteine at the same time of day and 0-8 hour urine collections were always made. This is important, as other studies ${ }^{9}$ have found that the activity of cysteine oxygenase is diurnal, being greatly reduced at night. Kupfer and Idle, while agreeing with the previously reported values for poor sulphoxidisers of $S$ carboxymethyl-L-cysteine within the general population, have pointed out that there may exist a subset of the population who are 'delayed excreters'. ${ }^{10}$ These subjects produce sulphoxide metabolites in the 8-24 hour period, presumably via a different enzymic pathway. Further investigations of poor sulphoxidisers may show whether the distinction between the two subsets ('intrinsically poor' and 'delayed excreters') is useful clinically. ${ }^{10}$

The prospective study, looking at sulphoxidation ability before and after three months' treatment with second line drugs, showed that there were no significant changes in SI after this introduction, regardless of the clinical response. The cross sectional study confirmed that there was no association or trend between a poor SI and any particular drug. As these drugs act over a period of several months it might be suggested that three months is too short a period to exclude an effect on sulphoxidation. This is unlikely to be the case as profound effects were seen on the disease processes, indicating the effectiveness of drug action. Despite this, no patient changed phenotype from good to poor sulphoxidiser (or vice versa) over the period of the study. Hence, the second line agents used in this study apparently do not induce or inhibit the enzyme systems responsible for sulphoxidation of $S$-carboxymethyl-L-cysteine. The effect of the acute phase response was analysed by looking at the SI values of patients at the height of disease activity and then later when the response was reduced by $50 \%$ as measured by CRP and ESR. There were, however, no significant differences in SI at the two time points measured. This absence of an association was confirmed in the cross sectional study where no suggestion of a correlation was found between SI and measures of disease activity (table 3 ). In addition, no correlations were found in nonresponder patients without change in their acute phase response. It therefore appears that poor sulphoxidation is a stable clinical marker not significantly influenced by significant changes in the acute phase response or by three months' treatment with second line drugs. In a previous study we showed that there is no association between the HLA-DR status (which is the recognised genetic risk factor for $R A$ ) and sulphoxidation. ${ }^{3}$ There seem therefore to be two separate genetic factors associated with RA and, possibly, these might be used as prognostic parameters early in disease. Preliminary evidence from a four year follow up of patients with early arthritis suggests that this approach may be clinically useful. ${ }^{11}$

The results of this current study suggest that there is an association between poor sulphoxidation ability and inflammatory joint disease. The cytosolic enzyme which converts $S$ carboxymethylcysteine to its sulphoxide metabolites is believed to be identical ${ }^{9}$ with cysteine oxygenase, which converts cysteine to cysteine sulphinic acid. This is the first step in the pathway which forms inorganic sulphate levels, as the supply of this anion in vivo is believed to be largely controlled by cysteine oxidation via the cysteine oxygenase route. Decreased availability of inorganic sulphate would be expected to affect production of tissue components, such as chondroitin sulphate, which have a large number of sulphated residues. ${ }^{12}$

Decreased formation of paracetamol sulphate after paracetamol administration has been noted in patients with RA. ${ }^{13}$ This may reflect a general reduction in sulphation of both endogenous and exogenous components, ${ }^{14}$ which might affect the disease process. There is experimental support for this, in that iodoacetate, which depletes thiol groups, has been used in animal models as a means of inducing cartilage damage. ${ }^{15}$ These variations in immune response and tissue composition might then influence the disease process in RA. Furthermore, the level of free thiols is known to be important in maintaining the immune response, including the conservation of rheumatoid factor and complement receptor structure. ${ }^{15}$

In conclusion, we have shown that three quarters of patients with RA have a defective ability to oxidise sulphur, and that this is not the consequence of an abnormal acute phase response or second line drugs. The role of this enzyme system in the aetiopathogenesis of this disease requires elucidation.

The work was supported by the Arthritis and Rheumatism Council

1 Mitchell S C, Waring R H. S-oxidation. In: Damani L A, ed. S-Oxygenase III human pharmacogenetics in sulphur-containing drugs and related organic compounds. Vol 2B. Chichester Ellis Horwood, 1989: 101-19.

2 Waring $R$ H. Pharmacogenetics of the S-oxidation of S-carboxymethyl-L-cysteine. Drug Metab Dispos 1988; 6: 253-63.

3 Emery P, Panayi G S, Huston G, et al. D-penicillamineinduced toxicity in rheumatoid arthritis: the role of sulphoxidation status and HLA-DR3. F Rheumatol 1984, sulphoxidation $626-32$.

4 Madhok R, Capell H A, Waring R H. Does sulphoxidation state predict gold toxicity in rheumatoid arthritis? $B M \mathcal{F}$ 1987; 294: 483 .

5 Olomu A B, Vickers C R, Waring R H, et al. High incidence of poor sulphoxidation in patients with primary biliary cirrhosis. NEnglf Med 1988; 318: 1089-92.

6 Scadding G K, Ayesh R, Brostoff J, Mitchell S C, Waring R H, Smith R L. Poor sulphoxidation ability in patients with food sensitivity. BMF 1988; 297: 105-7.

7 Steventon G, Waring R H, Williams A C, Pall H, Adams D. Xenobiotic metabolism in motorneurone disease. Lance 1988; ii: $644-7$.

8 Mitchell S C, Waring R H, Haley C S, Idle J R, Smith R L. Genetic aspects of the polymodally distributed sulphoxidation of S-carboxymethyl-L-cysteine in man. Br $\mathrm{J}$ Clin tion of S-carboxymethyl-L-cys

9 Mitchell S C, Waring R H. Deficiency of the S-oxidation of S-carboxymethyl-L-cysteine. Pharmacol Ther 1990; 43: 237-49.

10 Kupfer A, Idle J R. False positives with current carbocisteine protocol for sulphoxidation protocol. Lancet 1990; 335: 1107.

11 Emery P, Bradley H, Arthur V, Yanes T T, Tunn E, Waring R H. Poor sulphoxidation: a genetically determined factor associated with persistent disease in rheumatoid arthritis. associated with persistent dis

12 Marriott C. Proteoglycans, structure, function and evaluation. In: Ganderton D, Jones T, eds. Drug delivery to the respira tory tract. Chichester: Ellis Horwood, 1987: 68-74.

13 Bradley H, Waring R H, Emery P, Arthur V. Metabolism of low-dose paracetamol in patients with rheumatoid arthritis. Xenobiotica. 1991; 21: 689-93.

14 Caroll G. Measurement of sulphated glycosaminoglycans and proteoglycan fragments in arthritic synovial fluid. Ann Rheum Dis 1989; 48: 17-24.

15 Hall $N$ D, Gillan A W. Effect of antirheumatic drugs on protein sulphydryl reactivity of human serum. $\mathcal{J}$ Pharm Pharmacol 1979; 31: 676-80. 